\title{
Exploring the potential of plant-derived natural products beyond functional food: applications in nanomedicine
}

\begin{abstract}
The use of plant products as nutritional food and therapeutic agents is immemorial and intimately linked to the human life since its origin. Also, the tanning action of plant extracts has been hugely exploited to transform animal skins into leather from ancient times to present. However, the exploitation of the potential applications of plant biomolecules in some of the modern technologies is rather now emerging. In fact, the antioxidant, reducing and biological activities of the plant metabolites together their chelating and their biodegradable properties, make the plant-derived natural products unique raw materials to design new sustainable approaches to prepare promising hybrid formulations and composite materials at the nanometer scale for innovative diagnostic and therapeutic procedures and nanotechnology applications. In the present contribution, some recent advances and present challenges in this topic are briefly discussed.
\end{abstract}

Keywords: Phytochemicals, Plant products, Nanomedicine, Nanotechnology
Volume 2 Issue 3 - 2015

\author{
Carlos Luna Criado, Raquel Mendoza- \\ Reséndez \\ Universidad Autonoma de Nuevo Leon, Mexico
}

Correspondence: Carlos Luna Criado, Universidad Autonoma de Nuevo Leon (UANL), Av. Universidad S/N, San Nicolas de los Garza, 66450 Nuevo Leon, Mexico, Tel 00(52)(8I)8329-4030 Email carlos.lunacd@uanl.edu.mx

Received: April 28, 2015 | Published: August 04, 2015

\section{Introduction}

Plants naturally generate antimicrobial and antioxidant biomolecules with exceptional biochemical properties that have played crucial roles in the survival of plants and which frequently produce therapeutic effects for the human health. These unique properties have been valued and exploited since immemorial times. For instance, a large variety of plant products have been extensively used as spices, not only for flavoring and coloring food, but also for their beneficial properties for health and because their preserve food with the inhibition of oxidation processes and growth of microorganisms. ${ }^{1}$ Furthermore, some of these natural products exhibit notorious analgesic, anti-inflammatory, anticancer, lipolytic and antihyperglycemic activities, among others,${ }^{2-5}$ which have constituted the basis of the most traditional medicines and that provide an endless source of active principles for current pharmaceutical drugs. ${ }^{5-7}$ Plant biomolecules have a versatile ability to interact with other compounds through a large variety of chemical reactions. ${ }^{8}$ In fact, the tanning action of plant polyphenols has been used in the making of leather since antiquity ${ }^{8,9}$ and the chelating and antibacterial abilities of algae and plant extracts improve the wastewater treatments. ${ }^{10,11}$ However, despite these interesting applications, it is obvious that the exploitation of the immense potential of the plant biomolecules in some of the modern technologies remains in an emerging state notwithstanding the advantages that it offers, including low cost, sustainability and a huge versatility. In this regard, the syntheses of functional colloidal nanoparticles mediated by plant extracts have rapidly become a topic of intensive investigation during recent years. ${ }^{12-14}$

Colloidal nanoparticles exhibit fascinating and unique sizedependent physicochemical properties as a consequence of their extremely reduced volume, which are revolutionizing numerous technological fields such as catalysis, ${ }^{15}$ sensor technology ${ }^{16}$ and nanoelectro-mechanical systems (NEMS). ${ }^{17}$ Also, they are becoming key pieces in combating cancer, which has remained the major public health problem since decades. In this manner, nanoparticles and quantum dots can improve the cancer imaging with the enhancement of the resolution of magnetic resonance imaging ${ }^{18}$ or by fluorescence signals, ${ }^{19}$ respectively. Also, nanoparticles can serve as nanovectors for drug delivery increasing the efficiency of chemotherapies ${ }^{20}$ and as nanoscopic heat sources for hyperthermia therapies in the presence of ac magnetic fields ${ }^{21}$ or electromagnetic radiation..$^{22}$ However, the technological exploitation of nanomaterials involves two serious problems to be urgently faced:

I. their preparation produces waste products with noxious effects on human health and the environment and

II. nano materials themselves can be harmful; ${ }^{23}$ in fact, some nano materials reduce the cell viability of human healthy cells and produce the inhibition of the metabolism and DNA damage, ${ }^{24}$ in addition, they can affect to the biological functions of in vivo systems, specially the aquatic ones. ${ }^{25,26}$

Both worrying problems could be partially resolved with the use of phytochemicals in the synthesis of the nanomaterials, replacing man-made reagents with harmful effects on human health and the environment by biodegradable and eco-friendly plant metabolites that simultaneously play a dual role as reducing agents and colloidal stabilizers. ${ }^{12-14}$ In addition, these "greener" syntheses are quite simple, economically competitive and frequently, "one-pot" processes. ${ }^{13,14,27-32}$ The plant metabolites are usually employed in these synthetic methods in the form of concentrated aqueous extracts of fruits, ${ }^{27,28}$ seeds, ${ }^{29}$ barks, ${ }^{30}$ chili peppers ${ }^{31,32}$ and leaves ${ }^{33}$ with high levels of antioxidant polyphenols. Also, plant metabolites processed by insects have showed astonishing antioxidant physicochemical properties, being aqueous solutions of honey ${ }^{34-37}$ and royal jelly ${ }^{38}$ excellent reaction media for the crystallization and stabilization of nanoparticles. The "cocktail" of phytochemicals that have these eco-friendly extracts or solutions can synergistically interact with metallic cations from dissolved salts to produce metallic, metal oxide and/or organometallic nanoparticles. ${ }^{12-14,27-38}$ Furthermore, the phytochemicals also coat the surface of the resulting nanoparticles providing them colloidal steric and/or electrostatic stabilization and new or enhanced functionalities. 
Therefore, these synthetic methods represent novel routes to attach multipurpose biomolecules to nanoparticle surface, providing them improved biological activities exploitable in diverse biomedical applications, including treatments against drug-resistant bacteria ${ }^{38}$ and cancer diagnosis and therapy. ${ }^{12}$ In this manner, several works have shown that gold nanoparticles capped by photochemicals are more biocompatible that gold nanoparticles capped with other surfactants ${ }^{39}$ and also display excellent affinity towards receptors on tumor cells and favor the nanoparticle internalization within cancer cells without affecting the cell viability. ${ }^{12}$ This is a promising result for the safe delivery of drugs and cancer imaging, ${ }^{12}$ and also it could be crucial for the massive use of nanomaterials without jeopardizing human health and the environment.

On the other hand, the well-known broad-spectrum antimicrobial activity of silver nanoparticles ${ }^{40-42}$ can be significantly enhanced when they are biosynthesized and coated by biomolecules of plants ${ }^{43}$ or metabolites of bee products. ${ }^{38}$ In this respect, it is pertinent to remark that the resistance of microbes against silver nanoparticles is generally poor and therefore, Ag nanoparticles could play an essential role in the prevention of epidemics caused by the progressive resistance of pathogens to the available antimicrobial drugs. ${ }^{40}$ Given the abovementioned technological potential, ${ }^{44,45}$ nanoparticles are increasingly present in the human daily life and their importance in the global market seems unstoppable, being the involved industries strongly competitive. In this framework, the major challenges of the biosynthesis mediated by phytochemicals to become competitive alternatives to obtain nanomaterials at industrial level, is to mass produce stable and very uniform nanoparticles with high reproducibility and engineered sizes and morphologies and controlled uniformity and aggregation states by the facile and reproducible modification of the synthetic parameters, in similar manner to synthetic methods such as co-precipitation, ${ }^{46}$ sol-gel, ${ }^{47}$ hydrothermal, ${ }^{48,49}$ thermal decomposition of salts, ${ }^{50}$ polyol process, ${ }^{51-53}$ electro deposition ${ }^{54}$ and chemical vapor deposition ${ }^{55}$ techniques, which are well-known and widely used.

In this respect, some works have pointed out that the uniformity and size of biosynthesized nanoparticles can be readily modulated with the variation of the $\mathrm{pH}$ of the reaction medium. ${ }^{35,56} \mathrm{Also}$, the modulation of the concentration ratio between the precursor salt and the organic extract usually allows control of the particle size. Typically, an increment of the extract concentration implies that the reactions occur faster and the particle concentration quickly increases. However, the stabilizing ability of the natural extracts is limited and it can be not enough to prevent particle growth by irreversible aggregation under high particle concentrations. In these conditions, we have found that biosynthesized silver nanocrystals tend to spontaneously form supramolecular structures by oriented attachment, ${ }^{38}$ coalescence $^{38}$ and/or Ostwald ripening. ${ }^{48}$ For example, sub-micrometric dendriticlike structures constituted by clusters of Ag nanocrystals that share the same crystallographic orientation have been obtained using aqueous royal jelly solutions and $0.5 \mathrm{M}$ aqueous solutions of silver nitrate $\left(\mathrm{AgNO}_{3}\right){ }^{38} \mathrm{On}$ the other hand, the variation of the $\mathrm{AgNO}_{3} /$ extract weight ratio in the synthesis of Ag nanoparticles mediated by extracts of Illicium verum (star anise) seeds yielded to the variation of the spatial distribution of the obtained nanoparticles:high $\mathrm{AgNO}_{3} /$ extract concentration ratios gave rise polydisperse particles randomly positioned, whereas for lower $\mathrm{AgNO}_{3}$ /extract ratios, particles of around $100 \mathrm{~nm}$ appeared decorated by very fine nanoparticles (with diameters of around $5 \mathrm{~nm}$ ), displaying these different states of nanoparticle aggregation interesting plasmonic properties. ${ }^{57}$

Another challenge to be faced is that the concentration and characteristics of the active bio-molecules in the natural plant extracts and bee products may significantly differ depending on the aging time of the natural product, the environmental conditions of the growing location and the way that they were extracted. Therefore, rigorous quality controls and well-standardized conditions to obtain the natural product extracts should be established to ensure the complete reproducibility of the biosynthetic processes.

\section{Conclusion}

In conclusion, green chemistry processes derived from the use of phytochemicals and metabolites of bee products seem very promising due to their effectiveness and their non-requirement of noxious reducing and stabilizing reagents, however, although significant advances have been achieved during the last decade, further investigations are needed to clarify and understand the composition and unique properties of phytochemicals. The progress of this fascinating topic should lead to new approaches to solutions of medical problems and interesting and innovative technologies involving more sustainable processes, nevertheless, the toxicity of the resulting products should be investigated in detail.

\section{Acknowledgments}

None.

\section{Conflicts of interest}

None.

\section{References}

1. Burdock GA, Carabin IG. Safety assessment of coriander (Coriandrumsativum L) essential oil as a food ingredient. Food and Chemical Toxicology. 2009;47(1):22-34.

2. Delaquis PJ, Stanich K, Girard B, et al. Anti microbial activity of individual and mixed fractions of dill, cilantro, coriander and eucalyptus essential oils. Int J Food Microbiol. 2002;74(1):101-109.

3. Liu RH. Health benefits of fruit and vegetables are from additive and synergistic combinations of phyto chemicals. Am J Clin Nutr. 2003;78(3):517S-520S.

4. Ikhlas A Khan, Ehab A, Abourashed. Leung's encyclopedia of common natural ingredients: used in food, drugs and cosmetics. John Wiley \& Sons, USA. 2011

5. Cross SE, Jin YS, Lu QY, et al. Green tea extract selectively targets nano mechanics of live metastatic cancer cells. Nanotechnology. 2011;22(21):215101

6. Farnsworth NR, Akerele O, Bingel AS, et al. Medicinal plants in therapy Bull world health organ. 1985;63(6):965-981.

7. Wichtl M. Herbal drugs and phytopharmaceuticals: a handbook for practice on a scientific basis (No. Ed. 3). Medpharm GmbH Scientific Publishers. 2004.

8. Quideau S, Deffieux D, Douat-Casassus C, et al. Plant polyphenols: chemical properties, biological activities, and synthesis. Angew Chem Int Ed Engl. 2011;50(3):586-621.

9. Norman R, Farnsworth, Djaja D, et al. Global importance of medicinal plants. The conservation of medicinal plants. 1991;25-51.

10. Hoffmann JP. Wastewater treatment with suspended and non suspended algae. Journal of Psychology. 1998;34(5):757-763.

11. Kolawole OM, Oguntoye SO, Agbede O, et al. Studies on the Efficacy of Bridelia Ferruginea Benth Bark Extract in Reducing the Coliform Load and BOD of Domestic Wastewater. Ethno botanical Leaflets. 2006;10:228-238.

12. Nune SK, Chanda N, Shukla R, et al. Green nanotechnology from tea: phytochemicals in tea as building blocks for production of biocompatible gold nanoparticles. J Mater Chem. 2009;19(19):2912-2920. 
13. Siavash I. Green synthesis of metal nanoparticles using plants. Green Chemistry. 2011;13(10):2638-2650.

14. Kharissova OV, Dias HR, Kharisov BI, et al. The greener synthesis of nanoparticles. Trends in biotechnology. 2013;31(4):240-248.

15. Perales Martínez IA, Rodríguez González V, Lee SW, et al. Facile synthesis of InVO 4/TiO2 hetero junction photo catalysts with enhanced photo catalytic properties under UV-vis irradiation. Journal of Photochemistry and Photobiology A: Chemistry. 2015;299:152-158.

16. Kneipp K, Wang Y, Kneipp H, et al. Single molecule detection using surface-enhanced Raman scattering (SERS). Phys Rev Lett. 1997;78(9):1667-1670.

17. Hierold C, Jungen A, Stampfer C, et al. Nano electro mechanical sensors based on carbón nano tubes. Sensors and Actuators A: Physical. 2007;136(1):51-61.

18. Bulte JW, Kraitchman DL. Iron oxide MR contrast agents for molecular and cellular imaging. NMR in Biomed. 2004;17(7):484-499.

19. Gao X, Cui Y, Levenson RM, et al. In vivo cancer targeting and imaging with semiconductor quantum dots. Nature biotechnology. 2004;22(8):969-976.

20. Peer D, Karp JM, Hong S, et al. Nano carriers as an emerging platform for cancer therapy. Nature nanotechnology. 2007;2(12):751-760.

21. Ito A, Kuga Y, Honda H, et al. Magnetite nanoparticle-loaded antiHER2 immuno liposomes for combination of antibody therapy with hyperthermia. Cancer lett. 2004;212(2):167-175.

22. Huang X, Jain PK, El-Sayed IH, et al. Plasmonic photothermal therapy (PPTT) using gold nanoparticles. Lasers in medical science. 2008;23(3):217-228.

23. Gatti AM. Nanomedicine and Nanopathology TwoOppositeAspects of Nanotechnologies. J Nanomed Res. 2014;1(2):00008.

24. Asha Rani PV, Low KahMun G, Hande MP, et al. Cytotoxicity and genotoxicity of silver nanoparticles in human cells. ACS nano. 2008;3(2):279-290.

25. Asharani PV, Wu YL, Gong Z, et al. Toxicity of silver nanoparticles in zebrafish models. Nanotechnology. 2008;19(25):255102.

26. Johari SA. Toxicity Effect of Colloidal Silver Nanoparticles on Fertilization Capacity and Reproduction Success of Rainbow Trout (Oncorhynchusmykiss). J Nanomed Res. 2014;1(1):00001.

27. Prathna TC, Chandrasekaran N, Raichur AM, et al. Biomimetic synthesis of silver nanoparticles by Citrus limon (lemon) aqueous extract and theoretical prediction of particle size. Colloids Surf B Bio interfaces. 2011;82(1):152-159.

28. Bankar A, Joshi B, Kumar AR, et al. Banana peel extract mediated novel route for the synthesis of silver nanoparticles. Colloids and Surfaces A: Physicochemical and Engineering Aspects. 2010;368(1):58-63.

29. Bar H, Bhui DK, Sahoo GP, et al. Green synthesis of silver nanoparticles using seed extract of Jatrophacurcas.Colloids and Surfaces A: Physicochemical and Engineering Aspects. 2009;348(1):212-216.

30. Sathishkumar M, Sneha K, Won SW, et al. Cinnamon zeylanicum bark extract and powder mediated green synthesis of nano-crystalline silver particles and its bactericidal activity. Colloids Surf B Biointerfaces. 2009;73(2):332-338.

31. Li S, Shen Y, Xie A, et al. Green synthesis of silver nanoparticles using Capsicum annuum L extract. Green Chem. 20079(8):852-858.

32. Mendoza RR, Núnez NO, Barriga CED, et al. Synthesis of metallic silver nanoparticles and silver organometallic nano disks mediated by extracts of Capsicum annuum var. aviculare (piquin) fruits. RSC $A d v$. 2013;3(43):20765-20771.
33. Song JY, Kim BS. Rapid biological synthesis of silver nanoparticles using plant leaf extracts. Bioprocess Biosyst Eng. 2009;32(1):79-84.

34. Philip D. Honey mediated green synthesis of silver nanoparticles. Spectro chim Acta A Mol Biomol Spectrosc. 2010;75(3):1078-1081.

35. Reddy SM, Datta KR, Sreelakshmi C, et al. Honey mediated green synthesis of $\mathrm{Pd}$ nanoparticles for suzuki coupling and hydrogenation of conjugated olefins. Nanoscience and Nanotechnology Letters. 2012;4(4):420-425.

36. Venu R, Ramulu TS, Anandakumar S, et al. Bio-directed synthesis of platinum nanoparticles using aqueous honey solutions and their catalytic applications. Colloids and Surfaces A: Physicochemical and Engineering Aspects. 2011;384(1):733-738.

37. Mendoza RR, Gómez TA, Barriga ED, et al. Synthesis of antibacterial silver-based nano disks and dendritic structures mediated by royal jelly. RSC Advances. 2014;4(4):1650-1658.

38. Sathishkumar M, Pavagadhi S, Mahadevan A, et al. Biosynthesis of gold nanoparticles and related cytotoxicity evaluation using A549 cells. Ecotoxicol Environ Saf. 2014;114:230-240.

39. Rai M, Yadav A, Gade A. Silver nanoparticles as a new generation of antimicrobials. Biotechnol Adv. 2009;27(1):76-83.

40. Panáček A, Koláŕ M, Večeřová R, et al. Antifungal activity of silver nanoparticles against Candida spp. Biomaterials. 2009;30(31):6333-6340.

41. Elechiguerra JL, Burt JL, Morones JR, et al. Interaction of silver nanoparticles with HIV-1. J Nanobiotechnology. 2005;3(6):1-10.

42. Antony JJ, Sivalingam P, Siva D, Kamalakkannan S, Anbarasu K, et al. (2011) Comparative evaluation of antibacterial activity of silver nanoparticles synthesized using Rhizophoraapiculata and glucose. Colloids and Surf B Bio interfaces. 2014;88(1):134-140.

43. Satyavani K, Gurudeeban SS. Green Revolution towards Nanobiotechnology. J Nanomed Res. 2014;2(1):00014.

44. Criado CL. Huge Avenues of Opportunities (With Some Potholes) Opened by the Very Small Things. J Nanomed Res. 2014;1(1):00005.

45. Kim YI, Kim D, Lee C S. Synthesis and characterization of $\mathrm{CoFe}_{2} \mathrm{O}_{4}$ magnetic nanoparticles prepared by temperature-controlled co precipitation method. Physica B: Condensed Matter. 2003;337(1):42-51.

46. Lu Y, Yin Y, Mayers B T, et al. Modifying the surface properties of super paramagnetic iron oxide nanoparticles through a sol-gel approach. Nano letters. 2002;2(3):183-186.

47. Luna C, Barriga-CastroE D, Mendoza-Reséndez R. The effects of aging time on the size, morphology, oriented attachment and magnetic behavior of hematite nanocrystals synthesized by forced hydrolysis of Fe III solutions. ActaMaterialia. 2014;66:405-413.

48. Chun JJ, Ling DS, Zheng GY, et al. Iron oxide tube-in-tube nanostructures. The J Phys Chem C. 2007;111(35):13022-13027.

49. Yu WW, Falkner JC, Yavuz CT, et al. Synthesis of mono disperse iron oxide nano crystals by thermal decomposition of iron carboxylate salts. Chem Commun (Camb). 2004 ;(20):2306-230.

50. Fievet F, Lagier JP, Blin B, et al. Homogeneous and heterogeneous nucleations in the polyol process for the preparation of micron and submicron size metal particles. Solid State Ionics. 1989;32-33(Part 1):198-205.

51. Sun Y, Xia Y. Large-Scale Synthesis of Uniform Silver Nano wires Through a Soft, Self-Seeding, Polyol Process. Advanced Materials. 2002;14(11):833-837.

52. Luna C, Morales M P, Serna C J, et al. Effects of surfactants on the particle morphology and self-organization of Co nano crystals. Materials Science and Engineering: C. 2003;23(6):1129-1132. 
53. Victor M Prida, Javier García, Lucia Iglesias, et al. Electroplating and magneto structural characterization of multi segmented Co54Ni46/ Co85Ni15 nano wires from single electrochemical bath in anodic alumina templates. Nanoscale Res Lett. 2013;8(1):263.

54. Sokolov AN, Yap FL, Liu N, et al. Direct growth of aligned open carbon nano tubes by chemical vapor deposition. Chemical Physics Letters. 2014;299:97-102.
55. Shikuo LI, Yuhua S, Anjian X, et al. Rapid, room-temperature synthesis of amorphous selenium/protein composites using Capsicum annuum L extract. Nanotechnology. 2007;18(40):405101.

56. Luna C, Chávez VH, Barriga Castro ED, et al. Biosynthesis of Silver Fine Particles and Particles Decorated with Nanoparticles Using the Extract of IlliciumVerum (Star Anise) Seeds. Spectrochim Acta A Mol Biomol Spectrosc. 2015;141:(43-50). 